\title{
Oomycete Plant Pathogens Use Electric Fields to Target Roots
}

\author{
P. van West, B. M. Morris, B. Reid, A. A. Appiah, M. C. Osborne, T. A. Campbell, S. J. Shepherd, and \\ N. A. R. Gow \\ Department of Molecular and Cell Biology, Institute of Medical Sciences, University of Aberdeen, Foresterhill, Aberdeen \\ AB25 2ZD, Scotland, U.K.
}

Submitted 1 June 2001. Accepted 17 April 2002.

\begin{abstract}
Plant roots generate electrical currents and associated electrical fields as a consequence of electrogenic ion transport at the root surface. Here we demonstrate that the attraction of swimming zoospores of oomycete plant pathogens to plant roots is mediated in part by electrotaxis in natural root-generated electric fields. The zones of accumulation of anode- or cathode-seeking zoospores adjacent to intact and wounded root surfaces correlated with their in vitro electrotactic behavior. Manipulation of the root electrical field was reflected in changes in the pattern of zoospore accumulation and imposed focal electrical fields were capable of overriding endogenous signals at the root surface. The overall pattern of zoospore accumulation around roots was not affected by the presence of amino acids at concentrations expected within the rhizosphere, although higher concentrations induced encystment and reduced root targeting. The data suggest that electrical signals can augment or override chemical ones in mediating short-range tactic responses of oomycete zoospores at root surfaces.
\end{abstract}

Additional keywords: chemotaxis, Phytophthora, Pythium.

Oomycete species from the genera Phytophthora and $P y$ thium are responsible for many devastating epidemic diseases of commercially important crops, the most notable of which resulted in the potato famine in Ireland in the 1840s. Targeting mechanisms of swimming biflagellated zoospores, released into the soil from asexual sporangia, play a key role in the ability of these pathogens to locate a new host to colonize at times of high rainfall and waterlogged soils (Gow et al. 1999).

It has long remained unchallenged that chemotaxis toward exudates is the main mechanism explaining zoospore accumulation around roots. However, few examples of specific chemo-attractants have been described to date, and most reports fail to distinguish whether test compounds actually induce directional swimming or, instead, immobilize the zoospore by inducing encystment (Cameron and Carlile 1978; Deacon and Donaldson 1993; Morris and Ward 1992;

Corresponding author: N. A. R. Gow; Telephone: +44 (0) 1224 273179; Fax: +44 (0) 1224 273144; E-mail: n.gow@abdn.ac.uk

Current address of B. Reid: Department of Biomedical Sciences, Institute of Medical Sciences, University of Aberdeen, Foresterhill, Aberdeen AB25 2ZD, Scotland, U.K.

Current address of S. J. Shepherd: Department of Biology, University of York, Heslington, York, YO10 5DD, England.

The first three authors contributed equally to the work.
Zentmyer 1961). Moreover, chemotaxis does not explain the conundrum that marked spatial differences exist in the sites of accumulation of zoospores at the root surface, because the zones of nutrient exudation are similar for all plant roots (Gow 1993; Gow et al. 1999; Hickman and Ho 1966; Miller et al. 1988; Zentmyer 1961). Root exudates and surface components of roots are capable of selectively inducing encystment of zoospores (Longman and Callow 1987), but the spatial pattern of accumulation of Pythium aphanidermatum zoospores was not affected when roots were coated with an alginate gel (Jones et al. 1991). This indicates that direct contact with the root or surface-associated encysting agents is not necessary for selective recruitment of zoospores to specific sites on the root. Therefore, there is presently no coherent explanation for reported observations of precise and diverse spatial patterns of zoospore accretion at root surfaces.

Eukaryotic organisms generate exogenous voltages and circulating endogenous ionic currents, due to the spatial segregation of ion pumps and ion channels in the cell membrane at distinct domains, or poles of cells and electrically contiguous tissues. The electrical fields created by these ionic currents may play important roles in the development and morphogenesis of eukaryotic cells and tissues (Jaffe 1985; Nuccitelli 1988; Robinson 1985; Zhao et al. 1999) and in repair of mammalian epithelial wounds (Sta Iglesias and Vanable 1998). Plant roots also generate external electrical currents and fields due to the flow of protons and other ions into and out of growing and wounded regions (Behrens et al. 1982; Hush et al. 1992; Miller and Gow 1989; Miller et al. 1988; Weisenseel et al. 1979). The apical region encompassing the root cap, meristematic, and elongation (growth) zone can be a site of inward or outward current, depending on plant species and growth conditions. Wound sites consistently show a large inward flow of positive ionic current and are, therefore, cathodic (Gow et al. 1999; Hush et al. 1992; Miller et al. 1988). The magnitude of these fields depends of a number of intrinsic and environmental parameters but the endogenous field at the surface of a root can be as much as $500 \mathrm{mV} \mathrm{cm}{ }^{-1}$ for roots immersed in highly resistive soil water (Gow et al. 1992; 1999). We showed previously that this is significantly greater than both the in vitro threshold for zoospore electrotaxis of Phytophthora palmivora and Pythium aphanidermatum, which is approximately 2 to $5 \mathrm{mV} \mathrm{cm}$, and saturation of the electrotactic response at approximately $100 \mathrm{mV} \mathrm{cm}^{-1}$ (Morris and Gow 1993; Morris et al. 1992). The theoretical possibility for electrotaxis in vivo is supported in this study, which demonstrates that zoospore electrotactic behavior in vitro predicted where zoospores accumulated around roots with known electrical profiles. Here we demonstrate that electrotaxis and electrically induced encyst- 
ment are two dominant mechanisms determining where zoospores accumulate at the root surface.

\section{RESULTS}

\section{Electric currents around plant roots.}

The electrical fields around roots of host and nonhost plant species were mapped using a voltage-sensitive vibrating microelectrode (Jaffe and Nuccitelli 1974). The roots of perennial rye grass (Lolium perenne) and wheat (Triticum sativum) seedlings had an outward flow of positive current around the root cap, meristematic, and elongation zones and were, therefore, anodic (Fig. 1A and B). The outward currents were found to be up to $7 \mathrm{mV} \mathrm{cm}^{-1}$ for rye grass and $13 \mathrm{mV} \mathrm{cm}^{-1}$ for wheat. The root hair zone and wound sites, irrespective of the site of wounding, were locally cathodic, with an inwardly directed current of up to $24 \mathrm{mV} \mathrm{cm}^{-1}$ for rye grass (Fig. 1C).

\section{In situ accumulation of zoospores at the root surface correlates with their in vitro electrotactic behavior.}

Zoospores of Phytophthora palmivora are anodotactic in vitro while those of Pythium aphanidermatum are cathodotactic (Morris and Gow 1993). Cathodotactic zoospores of Pythium aphanidermatum were presented to immersed rye grass roots (Fig. 2A and B). After 10 min, the zoospores accumulated at the cathodic root hair zone but not at the anodic apex. These zoospores were removed by gentle wiping and the same root was placed in the same buffer with anodotactic Phytophthora palmivora zoospores. This resulted in rapid accumulation of zoospores of Phytophthora palmivora at the apical region that had not been colonized previously by Pythium aphanidermatum (Fig. 2C). Phytophthora palmivora, however, also accumulated distally, presumably by a nongalvanotactic mechanism. Therefore, electrotaxis is not sufficient to explain all of the zoospore accumulation patterns observed at root surfaces. Reciprocally, anodotactic zoospores of Phytophthora palmivora accumulated at the anodic root tip but were repelled by cathodic wounds that were cut within the otherwise anodic apical region (Fig. 2D and E). Subsequent replacement of Phytophthora palmivora zoospores with cathodotactic Pythium aphanidermatum zoospores resulted in immediate accumulation of zoospores at the same wound site that was nonattractive for Phytophthora palmivora (Fig. 2F and G).

Similar localization patterns were obtained for Phytophthora palmivora with monocotyledon roots of barley (Hordeum vulgare) and wheat (Triticum sativum) and the dicotyledon roots of cress (Lepidium sativum) and cacao (Theobroma cacao) (data not shown). Zoospores of Phytophthora palmivora accumulated around the apical region of the roots and not at the wound sites. In contrast, zoospores of Pythium aphanidermatum accumulated around the distal mature region of the roots of barley, wheat, and cress and to wound sites made in the apical region of the root, as found for rye grass.

It is formally possible that exudates of the intact apex of roots act as net attractants for zoospores of Phytophthora palmivora and repellants for Pythium aphanidermatum, and that wound exudates contain compounds that attract Pythium aphanidermatum but repel zoospores of Phytophthora palmivora. The literature provides no supporting evidence for these hypotheses, although specific wound exudates are known. It has been reported, for example, that the phenolic compound acetosyringone (4-acetyl-2,6-dimethoxyphenol) is exuded from metabolically active wounded plant cells and is a chemoattractant for Agrobacterium tumefaciens (Ashby et al. 1987; Parke et al. 1987; Stachel et al. 1985). Therefore, we tested whether acetosyringone, placed in a microcapillary tube, acted as an attractant of zoospores of Pythium aphanidermatum
(Table 1). However, no significant differences in directional swimming of the zoospores toward acetosyringone were observed, and no induced encystment was stimulated, indicating that the Pythium aphanidermatum zoospores were not influenced by acetosyringone.

We also investigated whether the amino acids of root exudates act as attractants for zoospores of Phytophthora palmivora and Pythium aphanidermatum. We determined which amino acids were released from cocoa roots and calculated the concentration of these amino acids in the rhizosphere (Shepherd 2001). To investigate whether zoospore behavior and root targeting were altered in the presence of these amino acids, we added a mixture of amino acids ( $\mathrm{pH}$ 7.2) to immersed roots of rye grass at the estimated physiological amino acid concentration and at $10 \times$ this concentration. In the presence of amino acids at estimated rhizosphere concentrations, zoospores of Phytophthora palmivora and Pythium aphanidermatum accumulated at the characteristic anodic and cathodic sites, respectively. However, when a $10 \times$ amino acid concentration was used, zoospores of Phytophthora palmivora encysted more rapidly and accumulated less at the anodic areas of the root. Similar results were obtained when Pythium aphanidermatum zoospores were exposed to wounded roots in the presence of $10 \times$ amino acids. In this case, zoospores accumulated less at wound sites. The mobility of the zoospores was reduced greatly and zoospore encystment was accelerated (data not shown).

In order to establish whether the amino acid mixture actually induces directional swimming of the zoospores, we performed capillary tube swim-in experiments (Fig. 3). Microcapillary tubes were filled with $1 \times$ or $10 \times$ amino acid mixtures and placed in suspensions of zoospores of Phytophthora
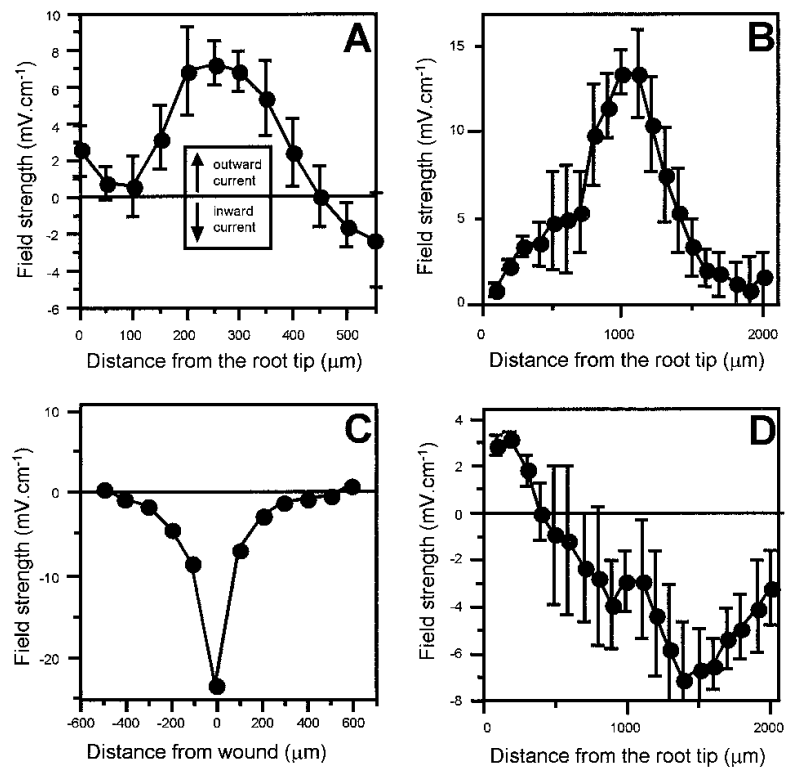

Fig. 1. Plant roots generate electrical fields. Electrical field profile around $\mathbf{A}$, a perennial rye grass (Lolium perenne) root tip and $\mathbf{B}$, roots of wheat (Triticum sativum). C, Electrical field profile around a perennial rye grass root tip after a new wound was created by incision into the outer cortex with a scalpel blade approximately $1.5 \mathrm{~mm}$ from the root tip. D, Endogenous electrical field of wheat roots after immersion in $1 \mu \mathrm{M}$ fusicoccin for $4.5 \mathrm{hr}$. Positive values represent an outward current (anodic region) and negative values an inward current (cathodic region). Error bars are $95 \%$ confidence limits for at least four independent roots. The roots were immersed in $2 \mathrm{mM}$ sodium phosphate buffer at $\mathrm{pH} 7.2$ and all measurements were made $50 \mu \mathrm{m}$ from the root surface. Three-day-old plant roots were obtained from germinated seeds as described before (Morris et al. 1995). 

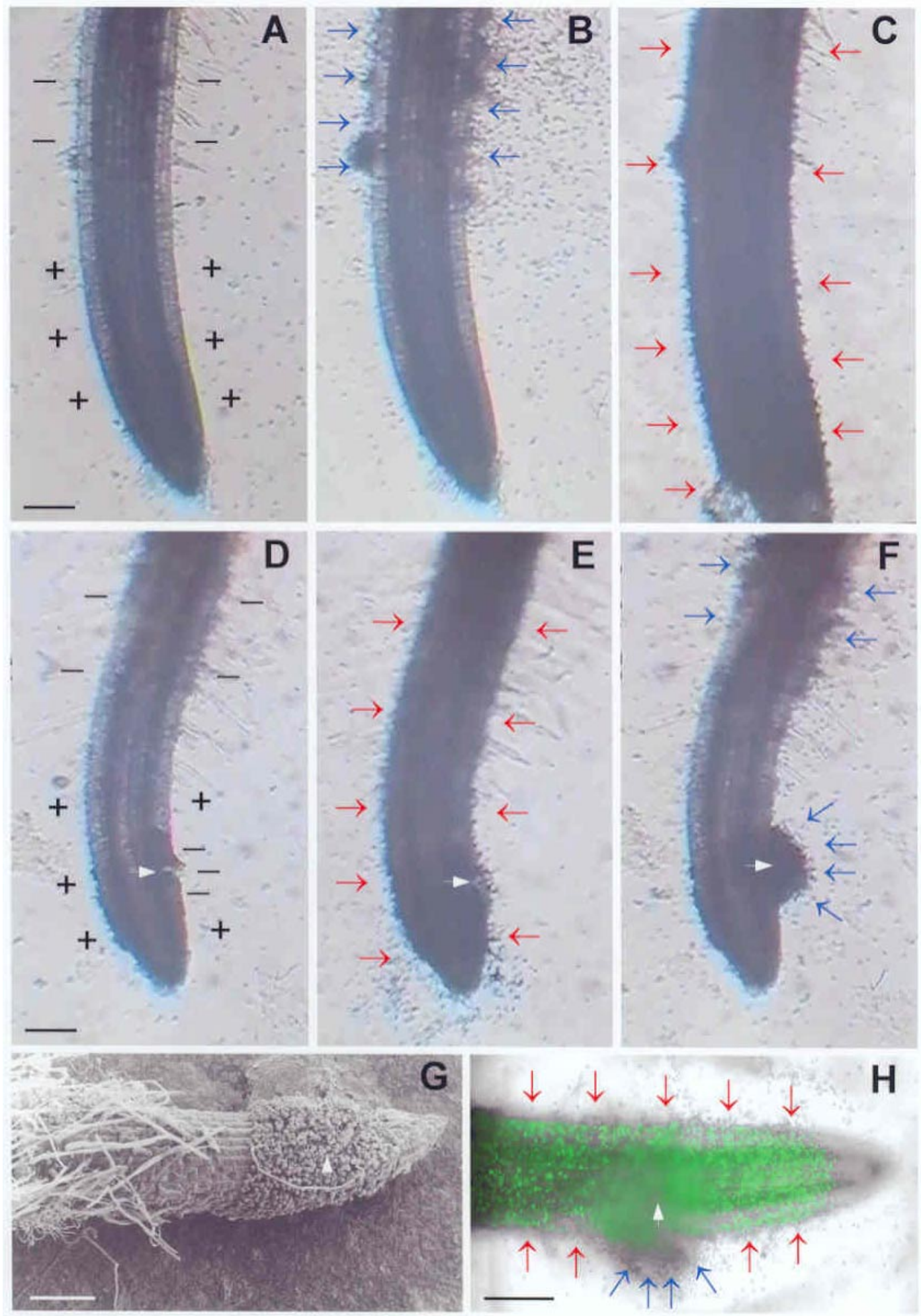

Fig. 2. Zoospore accumulation patterns correlate with root electrical field profiles. A, Pythium aphanidermatum zoospores (blue arrows) exposed to an intact rye grass root after $0 \mathrm{~min}$ and $\mathbf{B}$, accumulation to the rear of the root after $10 \mathrm{~min}$. C, Pythium aphanidermatum zoospores replaced by Phytophthora palmivora zoospores (red arrows) and photographed after $10 \mathrm{~min}$, showing extensive accumulation of zoospores at the root surface, including the apical region that repelled Pythium aphanidermatum zoospores. Accumulation of Phytophthora palmivora zoospores around root, but not at a wound site (white arrow) after D, 0 and E, 5 min. F, The same root but with Phytophthora palmivora zoospores replaced by Pythium aphanidermatum zoospores (blue arrows) and photographed after $5 \mathrm{~min}$. G, SEM of a wounded rye grass root infected with Pythium aphanidermatum zoospores showing highly localized accumulation of cysts at the wound site (white arrow) after 5 min. A and $\mathbf{B}$, Cathodic (-) and anodic (+) areas of the roots. $\mathbf{H}$, Rye grass root placed in a suspension of green fluorescent protein (GFP)-marked Phytophthora palmivora zoospores (van West et al. 1999), then wounded with a scalpel at the point indicated (white arrow). Zoospores of Pythium aphanidermatum (blue arrows) then were added and the root was photographed after 10 min. The fluorescence image is overlaid with a bright-field image and shows the accumulation of nonGFP Pythium aphanidermatum zoospores at the site of the wound. Scale bars represent $100 \mu \mathrm{m}$. 
palmivora or Pythium aphanidermatum. Little accumulation of zoospores was observed in capillary tubes containing $1 \times$ amino acids and only low numbers of zoospores of either species were found in the presence of $10 \times$ amino acids. Moreover, using image analysis, we were not able to detect directional swimming toward the $1 \times$ or $10 \times$ amino acid mixture (Fig. 3) or other nutrient solutions (Shepherd 2001). Therefore, amino acids did not affect swimming or root targeting when at rhizosphere concentrations, but increased encystment and reduced root targeting at higher concentrations, probably by inducing encystment close to the root surface. Therefore, both chemical and electrical gradients play a role in the homing, docking, and encystment of zoospores at the root surface.

We also investigated whether mixed zoospore populations of Phytophthora palmivora and Pythium aphanidermatum became segregated spatially as they accumulated around wounded and nonwounded roots of rye grass. Therefore, we made use of Phytophthora palmivora strains transformed with plasmid pVW2, which contains an optimized open reading frame of the gene encoding the green fluorescent protein (GFP) fused to a constitutive oomycete promoter (Ham34) (van West et al. 1999). Previously, we showed that Phytophthora palmivora transformants UY47p and UY64p expressed GFP in zoospores, cysts, germinated cysts, sporangia, and hyphae (van West et al. 1999). In addition, we determined the swimming speed of zoospores from UY47p (192 \pm 14 $\left.\mu \mathrm{m} . \mathrm{sec}^{-1}\right)$, UY64p $\left(172 \pm 13 \mu \mathrm{m} . \mathrm{sec}^{-1}\right)$, and the wild-type (170 $\left.\pm 20 \mu \mathrm{m} \cdot \mathrm{sec}^{-1}\right)$ and compared the trajectories of swimming of the zoospores by image analysis. GFP expression in UY47p and UY64p did not affect speed or pattern of zoospores swimming. Simultaneous zoospore inoculations of zoospores of Phytophthora palmivora UY47p and Pythium aphanidermatum resulted in spatial segregation of the anodotactic and cathodotactic species. GFP-expressing zoospores and cysts from UY47p were found predominantly at the anodic regions of the tested roots, but zoospores and cysts derived from Pythium aphanidermatum accumulated at cathodic (wounded) regions of the root (Fig. $2 \mathrm{H})$. From our mixed inoculation experiments and previous experiments (Reid et al. 1995), we also conclude that zoospores of Phytophthora palmivora were not attracted to cysts and zoospores from Pythium aphanidermatum, and vice versa. Therefore, the presence of cysts or zoospores from a different oomycete species did not influence the site of accretion at the root surface. In these mixed inoculation experiments, both zoospore species experienced the same endogenous chemical gradients. Therefore, they do not use chemotaxis to the same attractants to locate the root and may therefore use nonchemical signaling to locate the final site of encystment and accumulation.

\section{Wound age influences zoospore attraction.}

Wound sites of plant roots produce a large inward current (Hush et al. 1992; Hush and Overall 1989; Miller et al. 1988) (Fig. 1C). However, the magnitude of this induced electrical

Table 1. Pythium aphanidermatum does not respond to the woundreleased molecule acetosyringone

\begin{tabular}{lcccc}
\hline & \multicolumn{4}{c}{ Percentage polarization towards acetosyringone ${ }^{\mathbf{a}}$} \\
\cline { 2 - 5 } Time $(\mathbf{m i n})$ & $\mathbf{0} \boldsymbol{\mu M}$ & $\mathbf{0 . 1} \boldsymbol{\mu M}$ & $\mathbf{1 0} \boldsymbol{\mu M}$ & $\mathbf{1 ~} \mathbf{~ m M}$ \\
\hline $0-5$ & $-6.4 \pm 10.3$ & $-1.7 \pm 9.5$ & $0.1 \pm 10.1$ & $0.9 \pm 9.3$ \\
$10-15$ & $6.7 \pm 9.4$ & $7.2 \pm 9.8$ & $0.0 \pm 9.7$ & $2.3 \pm 9.5$ \\
$20-25$ & $5.7 \pm 9.7$ & $7.5 \pm 9.3$ & $-2.5 \pm 9.8$ & $3.9 \pm 9.5$ \\
\hline
\end{tabular}

${ }^{\mathrm{a}}$ Percentage polarization (\%P) was calculated for 200 zoospores per sample. Results are the means \pm SD of a range of times after exposure to the acetosyringone filled microcapillary tube. Polarization values were determined as has been described by Reid and associates (1995) and indicate taxis towards acetosyringone. field declines gradually within a period of $30 \mathrm{~min}$ to several hours and may undergo a reversal in polarity after this time (Hush et al. 1992; Hush and Overall 1989; Miller et al. 1988). For example, we found that the inward current at wound sites on cocoa roots and barley roots diminished rapidly to undetectable levels within 10 or $30 \mathrm{~min}$, respectively, when measured at a distance of up to $100 \mathrm{~m}$ from the wound surface (Fig. 4).

To further test the correlation between root-generated endogenous electrical current flow and zoospore accumulation, we measured zoospore attraction adjacent to fresh and older wounds (Fig. 5). Rye grass, cress, and wheat roots were wounded and the percentage accumulation of zoospores toward the wound was recorded. Zoospores of Pythium aphanidermatum showed no net directional swimming $(P=-3.8 \pm$ $6.13 \%)$ to the nonwounded apical region of the root. Immediately after wounding the root in the apical region, there was a large positive polarization $(55.8 \pm 2.61 \%)$ of zoospores swimming toward the wound site. Subsequently, the percentage orientation of zoospores swimming toward the wound site after 6 $\mathrm{h}$ dropped to $13.0 \pm 2.1 \%$. Accumulation of Pythium aphanidermatum zoospores at wound sites of wheat and cress showed similar trends. The magnitude of fresh wound currents in barley declined to 5 to $25 \%$ of the initial field of $250 \pm 140$ $\mathrm{mV} \mathrm{cm}{ }^{-1}$ after $30 \mathrm{~min}$ and to 0 to $12 \%$ after $2 \mathrm{~h}$ (Fig. 4). Correspondingly, the polarity of swimming of Pythium aphanidermatum adjacent to wounds of barley roots also declined to 52 and $27 \%$ of the original value by $30 \mathrm{~min}$ and $2 \mathrm{~h}$, respectively (data not shown). Therefore, a declining cathodic current around wound sites correlated with declining attraction of cathodotactic zoospores of Pythium aphanidermatum.

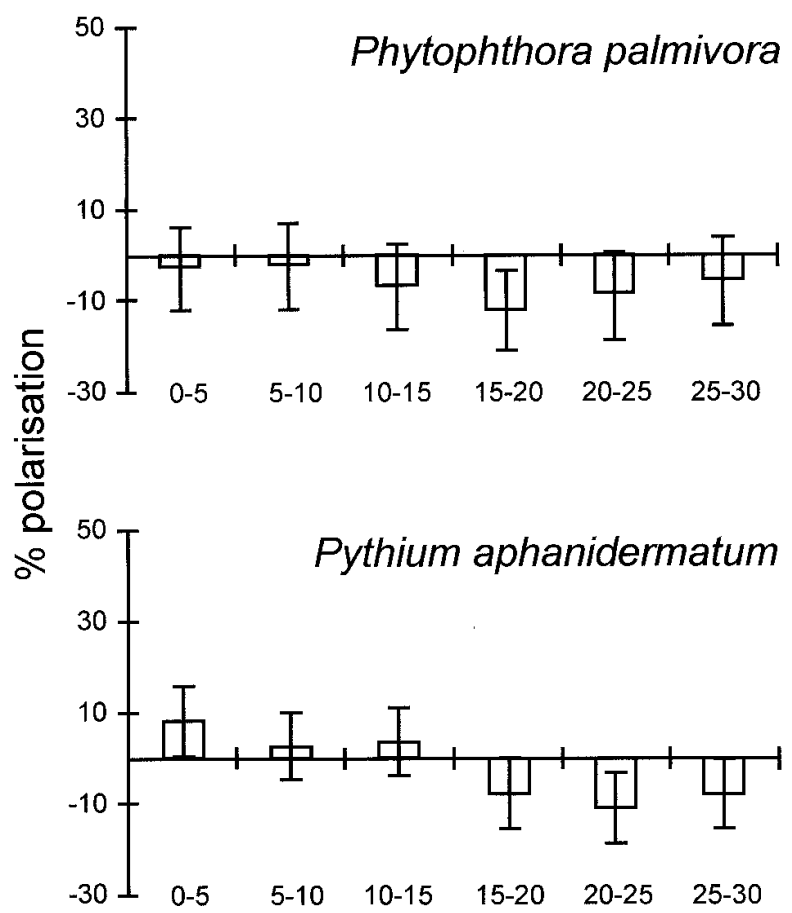

\section{Time interval $(\mathrm{min})$}

Fig. 3. Zoospores from Phytophthora palmivora and Pythium aphanidermatum do not show directional swimming towards a mixture of amino acids. The swimming response of zoospores from Phytophthora palmivora and Pythium aphanidermatum to a capillary tube containing a mixture of amino acids at similar concentrations to root exudates of cacao was determined over a period of $30 \mathrm{~min}$. Positive percentages indicate directional swimming toward the amino acid mixture, and negative percentages indicate that zoospores are swimming away from the amino acid mixture. Error bars are 95\% confidence intervals $(n=200)$. 


\section{Manipulation of the endogenous electric field of roots influences the pattern of zoospore accumulation.}

The pattern of endogenous electrical fields around roots is influenced by exposure to plant growth regulators, nutrients, and toxins (Miller and Gow 1989). To manipulate the profile of the root-generated electrical current and observe the consequences to the taxis of zoospores adjacent to the root surface, we used exogenous application of a fungal toxin, fusicoccin. The direction of swimming of individual zoospores was examined adjacent to control roots, fusicoccin-treated roots, and wounded roots (Table 2). Immersion of wheat roots in $1 \mu \mathrm{M}$ fusicoccin (Miller and Gow 1989) caused reversal of the polarity of the electrical field from anodic to weakly cathodic (Fig. 1D). The response of Pythium catenulatum zoospores, which are not electrotactic in vitro at physiological strength fields (Morris and Gow 1993), was unchanged under the three different conditions. Anodotactic Phytophthora palmivora zoospores displayed positive taxis to intact anodic root areas and reduced swimming toward the root adjacent to a cathodic wound. Electric-field reversal induced by fusicoccin treatment was less than the threshold field required to induce electrotactic-mediated repulsion of Phytophthora palmivora zoospores from the root (Fig. 1D). However, for zoospores of Pythium aphanidermatum, wounding within the anterior root region and treatment of roots with fusicoccin established a cathodic region at the root apex and increased the net polarization of
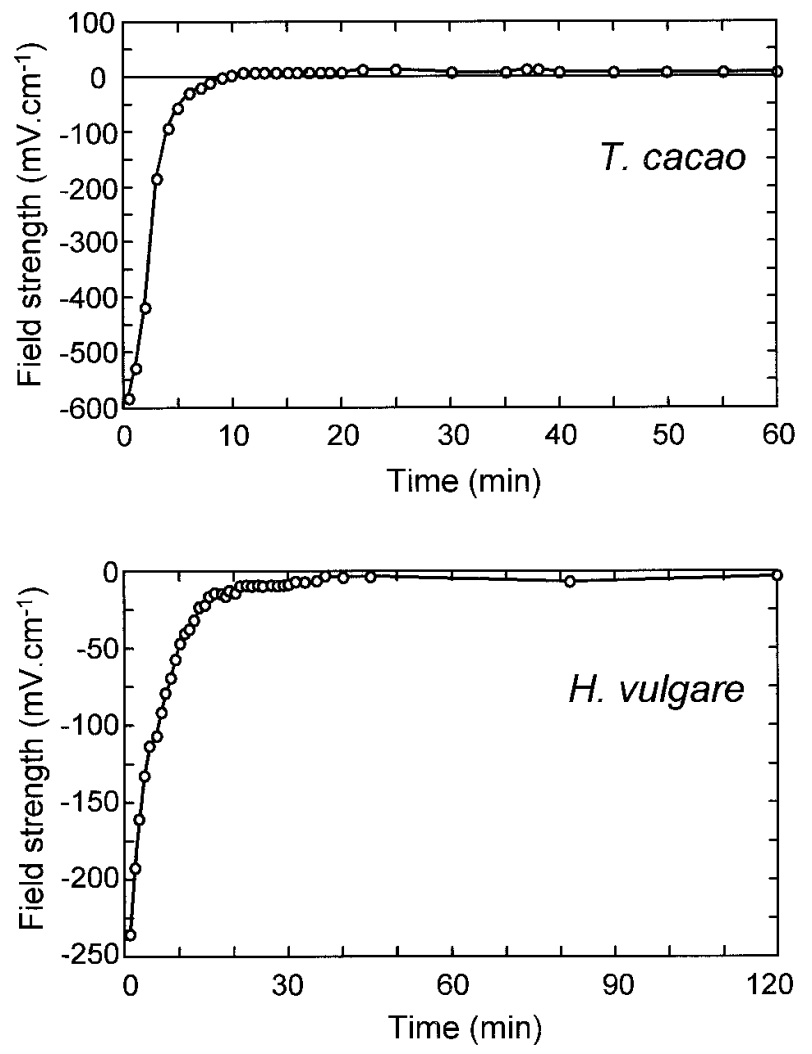

Fig. 4. The local electrical field at wounded roots declines over time. A, Typical variation of electrical field of a wound $2 \mathrm{~mm}$ behind the tip on a root of Theobroma cacao. An inward current of $26.04{\mathrm{mV} . \mathrm{cm}^{-1}}^{\text {was }}$ measured prior to wounding of a 20-day-old root. The root was immersed in artificial pond water at $\mathrm{pH} 7.3$ (Miller et al. 1988) and the temperature was $28 \pm 1^{\circ} \mathrm{C}$. B, Electrical field of a wound $1.5 \mathrm{~mm}$ behind the tip of a 14-day-old root of Hordeum vulgare. An outward current of $8.4 \mathrm{mV} . \mathrm{cm}^{-1}$ was measured prior to wounding. The root was immersed in artificial pond water ( $\mathrm{pH}$ 7.18) (Miller et al. 1988), and the temperature was $22 \pm$ $1{ }^{\circ} \mathrm{C}$. Vibrating microelectrode measurements were made $100 \mu \mathrm{m}$ from the surfaces of the roots. swimming towards the root. These results support the finding that accumulation of zoospores at electrogenic root surfaces correlates with their electrotactic behavior.

\section{Electro-encystment and autotaxis also promote recruitment of zoospores.}

Pythium aphanidermatum zoospores apparently respond to natural focal electrical fields around wounds; therefore, we used focally applied electrical fields of a physiological strength to further examine the effect of imposed electric fields on Pythium aphanidermatum zoospore accumulation. Glass microcapillary tubes were used to establish focal electrical fields of $85 \mathrm{mV} \mathrm{cm}{ }^{-1}, 100 \mu \mathrm{m}$ from the electrode tip. This field magnitude is well below the size of the largest electrical fields generated by roots (Gow et al. 1999). Imposed local cathodic fields exposures of only 1 min resulted in marked local aggregation of zoospores of Pythium aphanidermatum around the capillary tip (Fig. 6A and B). Zoospores dispersed rapidly when the field was turned off (Fig. 6C). When the focal field was applied for 5 min or longer, the electric field induced encystment of the zoospores (Fig. 6D and E), thereby demonstrating that electrical currents result in an accumulation of cysts over time. As mentioned above, we observed a similar accumulation pattern around certain areas around roots. This newly described phenomenon of "electro-encystment" may be an important mechanism in zoospore accumulation around roots, because it increases inoculum potential of the pathogen at a specific infection site. Control experiments using $\mathrm{pH}$ sensitive micro-electrodes placed at the mouth of the current-

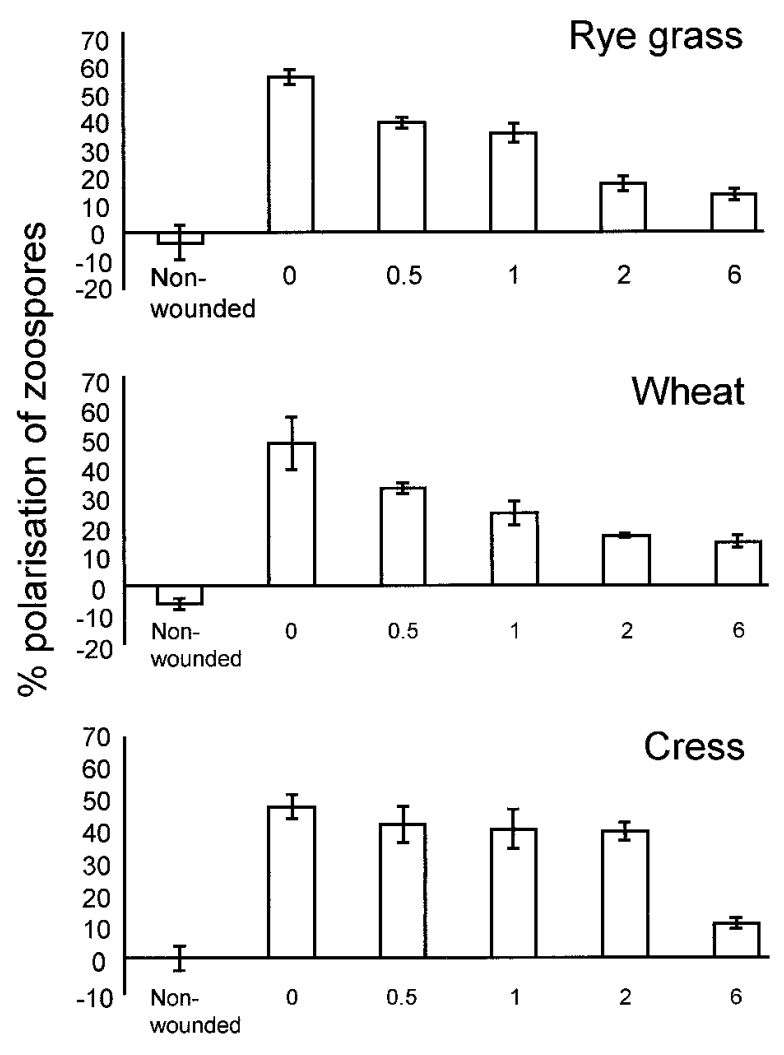

Time after roots were wounded $(h)$

Fig. 5. Wound age influences zoospore attraction. Roots from rye grass, wheat, and cress were inoculated with Pythium aphanidermatum zoospores at $0,0.5,1,2$, and $6 \mathrm{hr}$ after wounding. The percentage polarization was determined for three roots per plant species with 200 zoospores per time point analyzed. Polarization values were determined as has been described by Reid and associates (1995). 
carrying electrode showed no alteration in local $\mathrm{pH}$, indicating that the accumulation and encystment of zoospores was unlikely to be due to the presence of electrolytic products around the electrode.

A locally imposed cathodic electrical field generated by a microelectrode close to the root surface was able to override the normal repulsive nature of the (anodic) root apex for zoospores of Pythium aphanidermatum (Fig. 6F-H). The cathodic electric field, therefore, was dominant over local chemical gradients or weaker endogenous anodic fields that otherwise repelled Pythium aphanidermatum from the root apex. Once a significant aggregate of cysts had accumulated, zoospores continued to be recruited to the aggregation center, even when the electrode was removed (Fig. 6I). This presumably reflects autotactic behavior of zoospores to autoaggregates of cysts, which has been described previously (Ko and Chase 1973; Morris et al. 1995; Reid et al. 1995).

\section{DISCUSSION}

We have shown here that the profile of endogenous electrical fields generated by plant roots predicts where electrotactic species of zoospores accumulate. Induced or imposed electrical fields also were capable of overriding local chemical cues mediating attraction or repulsion in the rhizosphere. Our data provide evidence that the positive or negative electrotactic responses of zoospores (Katsura et al. 1966; Morris and Gow 1993; Troutman and Wills 1964) in endogenous electrical fields close to the root surface in the rhizosphere is the most plausible explanation for observations of marked asymmetries in the zones of accretion of different species of these zoospores (Gow et al. 1999; Morris et al. 1992). Accumulation of zoospores from Pythium aphanidermatum occurred predominantly in the root hair zone, at the base of root hairs. Inward currents, associated with emerging lateral roots, have been shown, for example, in Nicotiana tabacum (Miller et al. 1988) and in Phaseolus angularis (Hamada et al. 1992) roots. Accumulation of Phytophthora palmivora zoospores occurred mainly in the apical anodic zones of the roots under investigation, and these zoospores were excluded from wound sites despite the presence of a local ambient gradient of solutes exuded from the damaged tissue. The relative importance of root-generated chemical and electrical cues to the accumulation and encystment of zoospores on the root surface probably varies for different oomycete species and under different environmental conditions. However, electrical signals are capable of playing a dominant role in zoospore recruitment and plant root colonization. In vitro galvanotactic and galvanotropic responses of a wide variety of cell types has been described from microbes to neurites (Nuccitelli 1988; Robinson 1985). This article describes the first example of electrotaxis playing a major role in a plant-microbe interaction under natural conditions.
To date, no known specific chemo-attractants and chemo-repellents have been described that could explain the differential patterns of zoospore accumulation we and others have observed at different regions of the roots and at wound sites. Such observations would require that intact and wounded tissues at different parts of the root system act as point sources for attractants and repellents that have opposite influences on Phytophthora palmivora and Pythium aphanidermatum zoospores. Moreover, we analyzed the major extract components of roots of host (cacao) and nonhost (wheat) roots and found that many solutes induced zoospore encystment but few of the component amino acids and sugars induced bone fide directional swimming responses (Shepherd 2001). Many or most of these solutes also are found both in wounds and in root exudates. Competition experiments, in which solutions of amino acids were applied to roots and zoospores of Phytophthora palmivora or Pythium aphanidermatum, were used to assess the influence on chemotaxis upon root targeting. Concentrations of amino acids estimated to reflect normal rhizosphere concentrations did not affect swimming, encystment, or the accumulation patterns of zoospores around roots. At higher concentrations, zoospores encysted more rapidly in the medium and accumulation at the root surface was reduced, but little evidence was found for bona fide chemotaxis. This suggests that amino acids did, however, influence zoospore swimming and the ability of zoospores to locate roots. In addition, $P y$ thium aphanidermatum zoospores, which targeted wounds and other cathodic regions, displayed no taxis or induced encystment in the presence of 10 to $1,000 \mu \mathrm{M}$ acetosyringone, a specific wound metabolite. Therefore, chemotactic mechanisms cannot account fully for observations of the spatial differentiation of zoospore accretion at root surfaces. We suggest that electrotaxis augments other root targeting mechanisms and may override chemotaxis when chemotaxis affector molecules are at normal rhizosphere concentrations. Nonetheless, our data support the view that both chemotaxis and electrotaxis participate in the homing responses of zoospores toward roots.

New evidence presented here allows us to expand the sequence of events that form the homing response of zoospores in the rhizosphere. Initially, we assumed that zoospores are attracted to plant roots over relatively long distances by root exudates or that zoospores enter a zone of influence within the rhizosphere by random processes. So far, few chemical solutes from host plant exudates have been identified that illicit bone fide chemotaxis of zoospores. Those that do include two isoflavones of soybean, daidzein and genistein, which specifically attract zoospores of Phytophthora sojae (Morris and Ward 1992). We demonstrate here that, at relatively short distances from the root surface $(<500 \mu \mathrm{m})$, electrochemical gradients attract zoospores to specific regions in a spatially precise manner. These regions may be anodic or cathodic depending on the net ionic flux adjacent to the root cortex. Zoospore electrotaxis

Table 2. Zoospores of different oomycete species exhibit different tactic responses to wheat roots ${ }^{\mathrm{a}}$

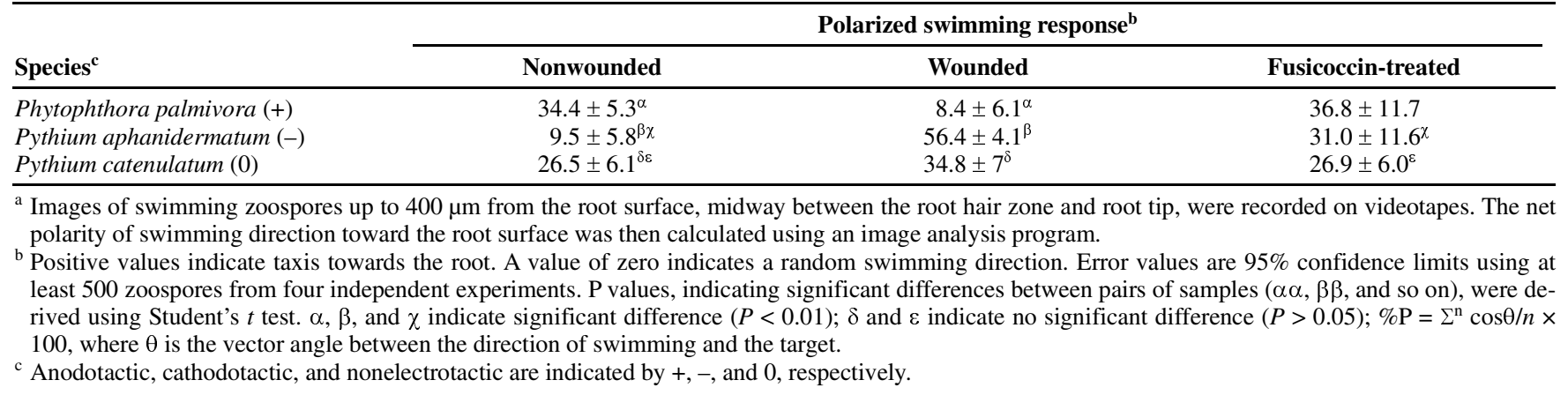


apparently depends on the charge dipole of the zoospore, which is determined in turn by the relative charge of surface glycoproteins on the anterior and posterior flagella (Morris and Gow 1993). The initial response of a zoospore to an electrical field is primarily one of directional swimming (Table 2). Close to the root, the turning frequency of the zoospore also is increased, ensuring that the zoospore remains close to the susceptible target region (Morris and Gow 1993). Surface interactions between zoospore and root and locally high solute concentrations stimulate encystment. We show here that encystment also can be induced by physiological-strength electrical fields and, therefore, by endogenous fields generated by plant roots. The accumulation of encysting zoospores forms cyst aggregates which also act as local attractors for other zoospores to accumulate and encyst, creating a positive feedback loop. This autoaggregation process may be induced due to the release of a chemo-attractant from the cysts that is recognized only by zoospores of the same genus, resulting in an increased inoculum potential (Reid et al. 1995). We envisage that electrotaxis will result in the selective colonization of living rather than dead roots, therefore maximizing population survival.

The molecular mechanisms of how electrotaxis is regulated and which proteins are involved remain unknown at present. The transduction of electrical signals into physiological responses by zoospores may involve voltage-dependent anion channels, calcium channels, and mechanosensitive channels because these proteins have been implicated in galvanotropic and galvanotactic responses (Cooper and Schliwa 1985; Davenport and Kater 1992; Dolle and Nultsch 1987; Onuma and Hui 1988). Therefore, we recently have started to analyze genes encoding channel proteins in order to establish their role in electrotactic responses of zoospores.

The relevance of our findings is broad because most tissues and organs of fungi, plants, and animals generate local electrical fields that are capable of influencing cellular behavior of self or nonself cells (Gow and Morris 1995; Jaffe 1981; McCaig and Zhao 1997; Nuccitelli 1988; Sta Iglesia and Vanable 1988; Zhao et al. 1999). These studies suggest that not all aspects of the interactions between host and parasites are mediated by chemical or thigmotropic signals and that there is an electrochemical dimension to spatial ecology and developmental biology that, thus far, has been largely ignored.

\section{MATERIALS AND METHODS}

\section{Strains and culture conditions.}

Phytophthora palmivora, Pythium aphanidermatum, and Pythium catenulatum cultures routinely were grown on V8 medium as has been described before (Morris et al. 1992; Reid et al. 1995). Phytophthora palmivora isolate P6390 was kindly supplied by M. D. Coffey (University of California, Riverside, U.S.A.). Pythium aphanidermatum and Pythium catenulatum were kindly supplied by J. Deacon (University of Edinburgh, UK). All species were grown under license from the Scottish
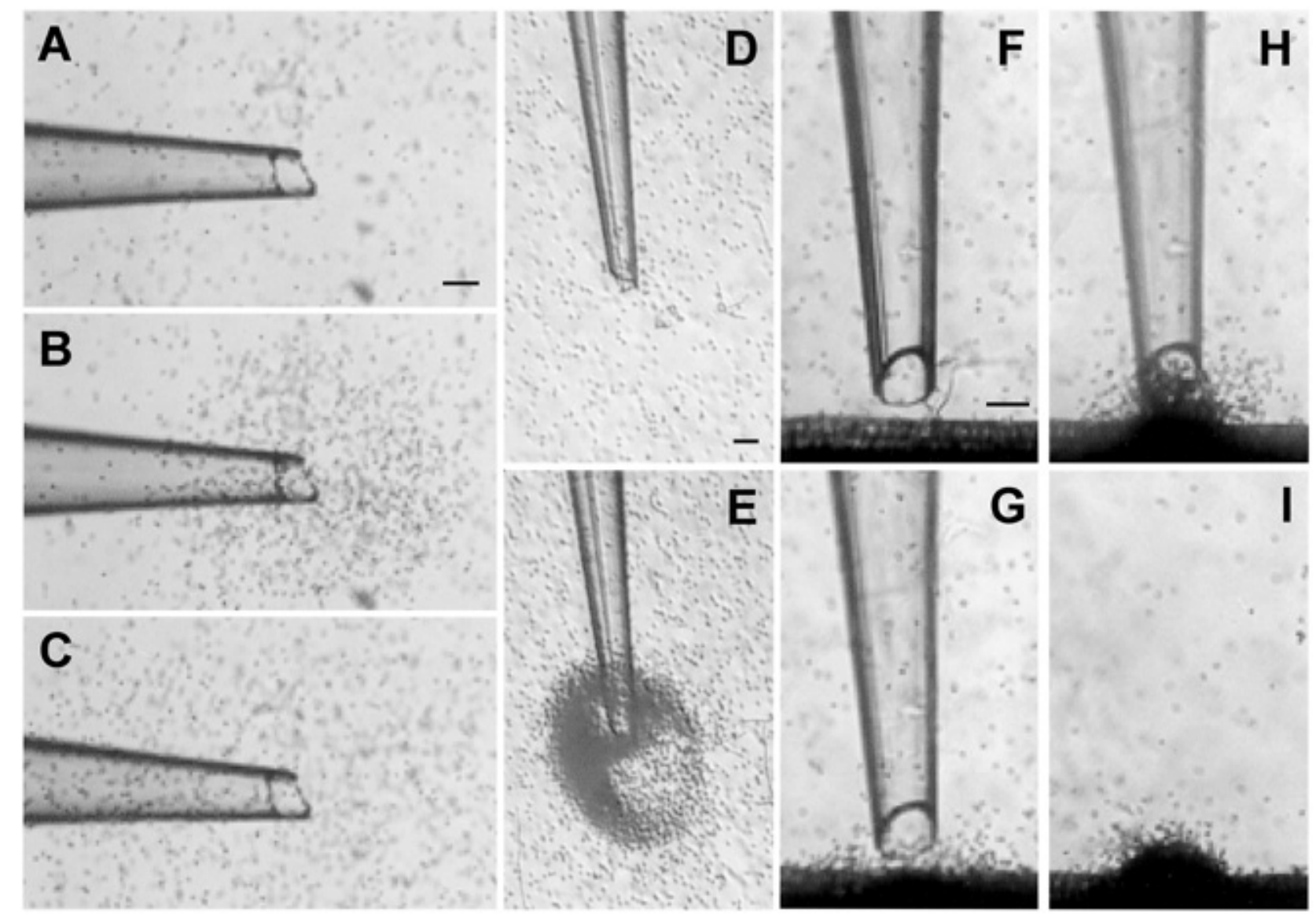

Fig. 6. Focal cathodic electrical fields induce attraction and encystment of Pythium aphanidermatum zoospores and recruit zoospores to otherwise nonattractive root surfaces. A, Zoospores of Pythium aphanidermatum are shown randomly around the tip of a glass electrode prior to the electrical field is switched on. B, Local accumulation of swimming zoospores $1 \mathrm{~min}$ after the electrical field is turned on (electrode cathodic), followed by dispersal of the zoospores C, 1 min after the electrical field was turned off. Induced encystment of zoospores around the tip of an electrode $\mathbf{D}$, at time zero and E, after prolonged (5 $\mathrm{min}$ ) exposure to the electrical field. F-I, Accumulation and encystment around the tip of a glass electrode (cathodic) placed approximately 50 $\mu \mathrm{m}$ from the surface of a root adjacent to the anodic apical region. Pictures were taken at 2-min intervals. F, Time point 0 . I, The electrode was taken out of the suspension and zoospores continued to accumulate at the root site. Scale bars represents $50 \mu \mathrm{m}$. 
Ministry of Fisheries and Food (license PH/2/1999). GFP-expressing isolates (UY47p and UY64p) were obtained following transformation of Phytophthora palmivora strain P6390 with transformation vector $\mathrm{pVW} 2$, containing a mammalian enhanced open reading frame of GFP (Clontech Laboratories, Inc., Palo Alto, CA, U.S.A.) fused to the Ham34 promoter and terminator sequences of Bremia lactucae (Judelson and Michelmore 1991), as described previously (van West et al. 1999).

Zoospores from Phytophthora palmivora were obtained by first collecting sporangia from 4-day-old cultures in $2 \mathrm{mM}$ sodium phosphate buffer ( $\mathrm{pH}$ 7.2). The suspension was cold shocked at $-18^{\circ} \mathrm{C}$ for $4 \mathrm{~min}$. Zoospores were released at room temperature after $30 \mathrm{~min}$. The suspension then was filtered through a Whatman No. 54 filter paper in order to obtain a pure suspension of zoospores. Pythium aphanidermatum zoospores were obtained by placing strips of V8 agar containing 4-day-old mycelium in $2 \mathrm{mM}$ sodium phosphate buffer $(\mathrm{pH}$ 7.2) and left at room temperature for 3 to $4 \mathrm{~h}$. Again, the suspension was filtered through a Whatman No. 54 filter paper.

\section{Growth of plant roots and infection assays.}

Seeds were surface sterilized in $0.5 \%$ chlorine bleach and placed on paper in petri dishes to allow germination. Seedlings with an average root length of 1 to $2 \mathrm{~cm}$ were placed in the center of a 5-cm petri dish and then secured with a small amount of Blue Tac. The seedlings then were immersed with a zoospore suspension in buffer ( $2 \mathrm{mM}$ sodium phosphate, $\mathrm{pH} 7.2$ ). Plant roots were wounded with a fine scalpel blade. The wound usually was made at the apical region of the root and punctured the cortical layers, and care was taken not to damage the conductive tissues of the stele. Results were recorded by video analysis using a Panasonic AG-6720 time-lapse videocassette recorder (Matsushita Electric Industrial Co. Ltd., Osaka, Japan) linked to a Panasonic WV-CD 52/B CCD camera attached to an Olympus CK40 inverted microscope. Results also were recorded by photographic analysis using a Nikon (F-601) camera attached to an Olympus Tokyo CK inverted microscope.

\section{Measurement of dynamics of zoospore swimming.}

Accumulation of the zoospores to wound sites or microcapillary tubes was recorded by video analysis as described above. The image analysis system described by Gray and Morris (1992) was used to determine the percentage polarization of zoospores to a wound site or capillary tube. A box was drawn onto an acetate sheet, which was placed on the video monitor over the area to be tested, and the direction of the swimming zoospores was recorded. This box corresponded to an area of 800 by $400 \mu \mathrm{m}$. The direction of swimming of the zoospores was recorded by using a black marker pen during video playback. This enabled vectors to be drawn with the computer, with the first vector from the capillary mouth or wound site to the zoospore and the second vector drawn from the zoospore out in the direction it was swimming. The vectors were able to give the angle of the capillary mouth or wound site in relation to zoospores and the angle between the direction of the zoospore swimming in relation to the capillary tube or wound site $(\theta)$. Subsequently, the percentage of polarization of swimming zoospores was determined with the formula: $\mathrm{P} \%=\Sigma^{\mathrm{n}} \cos \theta / n \times 100$.

This equation gives a percentage polarization value, where zero indicated no net directional swimming toward or away from the capillary tube or wound site. Positive percentages showed directional swimming toward the site and negative percentages swimming away from the site.

\section{Chemotaxis assays.}

Chemotaxis experiments were performed using microcapillary swim-in tests. A mixture of 14 amino acids was used that had been estimated to reflect that within the rhizosphere (Shepherd 2001). Cacao root exudates were collected in water over a period of 8 weeks and the concentration of each amino acid determined in an amino acid analyzer (420 Amino Acid Analyzer; PE Biosystems, Foster City, CA, U.S.A.). The amino acid concentration in the rhizosphere was estimated assuming that most solute was restricted to a plane extending 1 $\mathrm{mm}$ from the root surface. If the rhizosphere is assumed to extend beyond this zone, estimated rhizosphere concentrations would be proportionately lower. This model predicted that the 14 most common exudate amino acids would exist at the following concentrations: alanine $(20 \mu \mathrm{M})$, aspartic acid $(3 \mu \mathrm{M})$, cysteine $(1 \mu \mathrm{M})$, glutamic acid $(4 \mu \mathrm{M})$, glycine $(280 \mu \mathrm{M})$, isoleucine $(3 \mu \mathrm{M})$, leucine $(3 \mu \mathrm{M})$, lysine $(2 \mu \mathrm{M})$, methionine $(1$ $\mu \mathrm{M})$, proline $(5 \mu \mathrm{M})$, serine $(30 \mu \mathrm{M})$, threonine $(9 \mu \mathrm{M})$, tyrosine $(5 \mu \mathrm{M})$, and valine $(8 \mu \mathrm{M})$. Amino acids were dissolved in $2 \mathrm{mM}$ sodium phosphate buffer at $\mathrm{pH}$ 7.2. This amino acid solution at $1 \times$ and $10 \times$ concentration was used for competition experiments, in which roots of rye grass were submerged in the amino acids together with zoospores from either Phytophthora palmivora or Pythium aphanidermatum. The $1 \times$ concentration was used for the swim-in experiments.

Fabrication of electrodes and electrical field measurement. Stainless steel, pre-insulated microelectrodes (Microprobe Inc., Clarksburg, MD, U.S.A.) were electrically arced at the tips, tapered, sharpened in acid, and mounted in gold holders. Then, a platinum ball 10 to $30 \mu \mathrm{m}$ in diameter was electroplated in platinum chloride. Microelectrodes were vibrated at an amplitude equal to twice the ball width $(\approx 20 \mu \mathrm{m})$ with a piezo-electric element (Vibrating Probe Company, Woodshole, MA, U.S.A.). The potential difference across the extremities of the vibration was measured with a two-phase, lock-in amplifier (E. G. \& G. Princeton Applied Research, Oak Ridge, TN, U.S.A.).) and recorded on a chart recorder (Houston Instruments, Gistel, Belgium). Calibration was carried out by applying a known current density with a constant current calibrator (model N-600; Vibrating Probe Co.). The resulting electrical field was then calculated from $\mathrm{E}=\mathrm{I}_{a} p$, where $\mathrm{E}$ is the electrical field strength in $\mathrm{V} \mathrm{cm}{ }^{-1}, \mathrm{I}_{\mathrm{a}}$ is the current density in amps $\mathrm{cm}^{-2}$, and $p$ is the resistivity in $\Omega \mathrm{cm}$ (Jaffe and Nuccitelli 1974; Nuccitelli 1988).

\section{ACKNOWLEDGMENTS}

We thank R. P. Hobson, G. W. Gooday, and A. M. Rajnicek for comments on the manuscript; and L. Jaffe and F. Harold for inspiration. These studies were supported by grants from the Natural Environment Research Council (NERC) for studentships to S. J. Shepherd, T. A. Campbell, and M. C. Osborne; Biotechnology and Biological Sciences Research Council (BBSRC) (1/PO7720 and 1/BRE13669) (P. van West and A. A. Appiah); and The Royal Society (P. van West.).

\section{LITERATURE CITED}

Ashby, A. M., Watson, M. D., and Shaw, C. H. 1987. A Ti plasmid-determined function is responsible for chemotaxis of Agrobacterium tumefaciens toward the plant wound product acetosyringone. FEMS (Fed. Eur. Microbiol. Soc.) Microbiol. Lett. 84:28-38.

Behrens, H. M., Weisenseel, M. H., and Sievers, A. 1982. Rapid changes in the pattern of electric current around the root tip of Lepidium sativum L. following gravistimulation. Plant Physiol. 70:1079-1083.

Cameron, J. N., and Carlile, M. J. 1978. Fatty acids, aldehydes and alcohols as attractants for zoospores of Phytophthora palmivora. Nature 271:448-449.

Cooper, M. S., and Schliwa, M. 1985. Electrical and ionic controls of tissue cell locomotion in DC electric fields. J. Neurosci. Res. 13:223-244.

Davenport, R. W., and Kater, S. B. 1992. Local increases in intracellular calcium elicit local filopodial responses in helisoma neuronal growth cones. Neuron 9:405-416. 
Deacon, J. W., and Donaldson, S. P. 1993. Molecular recognition in the homing response of zoosporic fungi, with special reference to Pythium and Phytophthora. Mycol. Res. 97:1153-1171.

Dolle, R., and Nultsch, W. 1987. Effects of calcium ions and of calcium channel blockers on galvanotaxis of Chlamydomonas reinhardtii. Bot. Acta 1:18-23

Gow, N. A. R. 1993. Nonchemical signals used for host location and invasion by fungal pathogens. Trends Microbiol. 1:45-50.

Gow, N. A. R., Campbell, T. A., Morris, B. M., Osborne, M. C., Reid, B., Shepherd, S. J., and van West, P. 1999. Signals and interactions between phytopathogenic zoospores and plant roots. Pages 285-305 in: Microbial Signaling and Communication. R. England, G. Hobbs, N. Bainton, and D. M. Roberts, eds. Society for General Microbiology Symposium 57. Cambridge University Press. Cambridge.

Gow, N. A. R., and Morris, B. M. 1995. The electric fungus. Bot. J. Scot. 4:263-277.

Gow, N. A. R., Morris, B. M., and Reid, B. 1992. The electrophysiology of root-zoospore interactions. Pages 173-192 in: Perspectives in Plant Cell Recognition, Society for Experimental Biology Seminar Series. Vol. 48. J. A. Callow and J. R. Green, eds. Cambridge University Press. Cambridge.

Gray, D. I., and Morris, B. M. 1992. A low cost video analysis system for the BBC master computer. Binary 4:58-61.

Hamada, S., Ezaki, S., Hayashi, K., Toko, K., and Yamfuji, K. 1992. Electric current precedes emergence of a lateral root in higher plants. Plant Physiol. 100:614-619.

Hickman, C. J., and Ho, H. H. 1966. Behavior of zoospores in plant-pathogenic phycomycetes. Annu. Rev. Phytopathol. 4:195-220.

Hush, J. M., Newman, I. A., and Overall, R. L. 1992. Utilization of the vibrating probe and ion-selective microelectrode techniques to investigate electrophysiological responses to wounding in pea roots. J. Exp. Bot. 176:56-64.

Hush, J. M., and Overall, R. L. 1989. Steady ionic currents around pea (Pisum sativum L.) root tips: The effects of tissue wounding. Biol. Bull. 176S:56-64.

Jaffe, L. F. 1981. The role of ionic currents in establishing developmental pattern. Philos. Trans. R. Soc. Lond. B Biol. Sci. 295:553-66.

Jaffe, L. F. 1985. Extracellular current measurements with a vibrating probe. TINS (Trends Neurosci.) 8:517.

Jaffe, L. F., and Nuccitelli, R. 1974. An ultrasensitive vibrating probe for measuring extracellular currents. J. Cell Biol. 63:614-628.

Jones, S. W., Donaldson, S. P., and Deacon, J. W. 1991. Behavior of zoospores and zoospore cysts in relation to root infection by Pythium aphanidermatum. New Phytol. 117:289-301.

Judelson, H. S., and Michelmore, R. W. 1991. Transient expression of foreign genes in the oomycete Phytophthora infestans using Bremia lactucae regulatory sequences. Curr. Genet. 19:453-459.

Katsura, K., Masago, H., and Miyata, Y. 1966. Movements of zoospores of Phytophthora capsici. I. Electrotaxis in some organic solutions (abstract). Ann. Phytopathol. Soc. Jpn. 32:215-20.

Ko, W. H., and Chase, L. L. 1973. Aggregation of zoospores of Phy tophthora palmivora. J. Gen. Microbiol. 78:79-82.

Longman, D., and Callow, J. A. 1987. Specific saccharide residues are involved in the recognition of plant root surfaces by zoospores of $P y$ thium aphanidermatum. Phys. Mol. Plant Pathol. 30:139-150.

McCaig, C. D., and Zhao, M. 1997. Physiological electrical fields modify cell behavior. BioEssays 19:819-826.
Miller, A. L., and Gow, N. A. R. 1989. Correlation between root-generated ionic currents, $\mathrm{pH}$, fusicoccin, indoleacetic acid, and the growth of the primary root of Zea mays. Plant Physiol. 89:1198-1206.

Miller, A. L., Shand, E., and Gow, N. A. R. 1988. Ion currents associated with root tips, emerging laterals, and induced wound sites in Nicotiana tabacum: Spatial relationship proposed between resulting electrical fields and Phytophthoran zoospore infection. Plant Cell Environ. 11:21-25.

Morris, B. M., and Gow, N. A. R. 1993. Mechanism of electrotaxis of zoospores of phytopathogenic fungi. Phytopathology 8:877-882.

Morris, B. M., Reid, B., and Gow, N. A. R. 1992. Electrotaxis of zoospores of Phytophthora palmivora at physiologically relevant field strengths. Plant Cell Environ. 15:345-353.

Morris, B. M., Reid, B., and Gow, N. A. R. 1995. Tactic responses of zoospores of the fungus Phytophthora palmivora to solutions of different $\mathrm{pH}$ in relation to plant infection. Microbiology 141:1231-1237.

Morris P. F., and Ward, E. W. B. 1992. Chemoattraction of zoospores of the soybean pathogen Phytophthora sojae, by isoflavones. Phys. Mol. Plant Pathol. 40:17-22.

Nuccitelli, R. 1988. Physiological electrical fields can influence cell motility, growth, and polarity. Adv. Cell Biol. 2:213-233.

Onuma, K. E., and Hui, S.-W. 1988. Electric field-directed cell shape changes, displacement, and cytoskeletal reorganization are calcium dependent. J. Cell Biol. 106:2067-2075.

Parke, D., Ornston, L. N., and Nester, E. W. 1987. Chemotaxis to plant phenolic inducers of virulence genes is constitutively expressed in the absence of the Ti plasmid in Agrobacterium tumefaciens. J. Bacteriol. 169:5336-5338.

Reid, B., Morris, B. M., and Gow, N. A. R. 1995. Calcium-dependent, genus-specific autoaggregation of zoospores of phytopathogenic fungi Exp. Mycol. 19:202-213.

Robinson, K. R. 1985. The response of cells to electrical fields: A review. J. Cell Biol. 101:2023-2027.

Shepherd, S. J. 2001. Pages 1-305 in: Analysis of Phytophthora palmivora zoosporogenesis and zoospore chemotaxis. Ph.D. thesis. University of Aberdeen, Department of Molecular and Cell Biology, Scotland, U.K.

Stachel, S. E., An, G., Flores, C., and Nester, E. W. 1985. A Tn3 lacZ transposon for the random generation of beta-galactosidase gene fusions: Application to the analysis of gene expression in Agrobacterium. EMBO (Eur. Mol. Biol. Organ.) J. 4:891-898.

Sta Iglesia, D. D., and Vanable, J. W. 1988. Endogenous lateral electric fields around bovine corneal lesions are necessary for and can enhance normal rates of wound healing. Wound Repair Regen. 6:531-542.

Troutman, J. L., and Wills, W. H. 1964. Electrotaxis of Phytophthora parasitica zoospores and its possible role in infection of tobacco by the fungus. Phytopathology 54:225-8.

van West, P., Reid, B., Campbell, T. A., Sandrock, R. W., Fry, W. E., Kamoun, S., and Gow, N. A. R. 1999. Green fluorescent protein (GFP) as a reporter gene for the plant pathogenic oomycete Phytophthora palmivora. FEMS (Fed. Eur. Microbiol. Soc.)Microbiol. Lett. 178:71-80.

Weisenseel, M. H., Dorn, A., and Jaffe, L. F. 1979. Natural $\mathrm{H}^{+}$currents traverse growing roots and root hairs of Barley (Hordeum vulgare L.). Plant Physiol. 64:512-518.

Zentmyer, G. A. 1961. Chemotaxis of zoospores for root exudates. Science 133:1595-1596.

Zhao, M., Forrester, J. V., and McCaig, C. D. 1999. A small, physiological electric field orients cell division. Proc. Natl. Acad. Sci. U.S.A 96:4942-4946. 